\title{
Improved Simulation of Edaphic and Manure Phosphorus Loss in SWAT
}

\author{
Amy S. Collick,* Tamie L. Veith, Daniel R. Fuka, Peter J.A. Kleinman, Anthony R. Buda, Jennifer L. Weld, \\ Ray B. Bryant, Peter A. Vadas, Mike J. White, R. Daren Harmel, and Zachary M. Easton
}

\begin{abstract}
Watershed models such as the Soil Water Assessment Tool (SWAT) and the Agricultural Policy Environmental EXtender (APEX) are widely used to assess the fate and transport of agricultural nutrient management practices on soluble and particulate phosphorus $(\mathrm{P})$ loss in runoff. Soil P-cycling routines used in SWAT2012 revision 586 , however, do not simulate the short-term effects of applying a concentrated source of soluble $P$, such as manure, to the soil surface where it is most vulnerable to runoff. We added a new set of soil $P$ routines to SWAT2012 revision 586 to simulate surface-applied manure at field and subwatershed scales within Mahantango Creek watershed in south-central Pennsylvania. We corroborated the new $P$ routines and standard $P$ routines in two versions of SWAT (conventional SWAT, and a topographically driven variation called TopoSWAT) for a total of four modeling "treatments". All modeling treatments included $5 \mathrm{yr}$ of measured data under fieldspecific, historical management information. Short-term "wash off" processes resulting from precipitation immediately following surface application of manures were captured with the new $P$ routine whereas the standard routines resulted in losses regardless of manure application. The new routines improved sensitivity to key factors in nutrient management (i.e., timing, rate, method, and form of $\mathrm{P}$ application). Only the new $\mathrm{P}$ routines indicated decreases in soluble $P$ losses for dairy manure applications at 1, 5, and $10 \mathrm{~d}$ before a storm event. The new $P$ routines also resulted in more variable $\mathrm{P}$ losses when applying manure versus commercial fertilizer and represented increases in total $P$ losses, as compared with standard $P$ routines, with rate increases in dairy manure application $\left(56,000\right.$ to $\left.84,000 \mathrm{~L} \mathrm{ha}^{-1}\right)$. The new $\mathrm{P}$ routines exhibited greater than $50 \%$ variation among proportions of organic, particulate, and soluble $\mathrm{P}$ corresponding to spreading method. In contrast, proportions of $\mathrm{P}$ forms under the standard $\mathrm{P}$ routines varied less than $20 \%$. Results suggest similar revisions to other agroecosystem watershed models would be appropriate.
\end{abstract}

\section{Core Ideas}

- Dynamic manure P routines were added to the conventional SWAT model.

- New P routines were corroborated in two versions of SWAT.

- New $P$ routines accurately simulated the $4 R$ effects of manure management.

Copyright $\odot$ American Society of Agronomy, Crop Science Society of America, and Soil Science Society of America. 5585 Guilford Rd., Madison, WI 53711 USA.

All rights reserved.

J. Environ. Qual. 45:1215-1225 (2016)

doi:10.2134/jeq2015.03.0135

This is an open access article distributed under the terms of the CC BY-NC-ND

license (http://creativecommons.org/licenses/by-nc-nd/4.0/).

Received 13 Mar. 2015.

Accepted 23 Dec. 2015

*Corresponding author (amy.collick@ars.usda.gov).
$\mathrm{R}$ EPRESENTATION OF DIFFUSE SOURCES of surficial phosphorus $(\mathrm{P})$ in runoff is a priority concern in agricultural watershed modeling. The Soil and Water Assessment Tool (SWAT), Agricultural Policy Environmental EXtender (APEX), and the Chesapeake Bay Model, in particular, have often driven recommendations and even policies related to local, regional, and multistate nutrient management programs such as the Chesapeake Bay Watershed Agreement (Chesapeake Executive Council, 2014). Sources of $P$ in surface runoff include readily available $P$ in soils (i.e., edaphic $P$ ), $P$ in various plant residues, and $\mathrm{P}$ in applied fertilizers and manures.

A combination of rain simulation and runoff monitoring studies has revealed consistent, positive relationships between soil $\mathrm{P}$ and dissolved $\mathrm{P}$ in runoff, dependent on soil $\mathrm{P}$ extract. In summarizing the literature, Vadas et al. (2005) demonstrated that a single extraction ratio relating soil test $\mathrm{P}$ to dissolved $\mathrm{P}$ concentrations in runoff was applicable across a broad range of soil properties and management conditions.

For all fertilizers and manures (dairy, beef, swine poultry, etc.), the rate of application, solubility of $\mathrm{P}$ in the amendment, and method and timing of application are critical factors in maximizing crop benefit and downstream water quality. Effective nutrient management and stewardship requires attention to these four interdependent factors, collectively referred to as the "4R" factors: Right placement, Right timing, Right rate, and Right form (IPNI, 2012).

Great advantage can be found in placing applied sources of $P$ below the surface, as long as soil disturbance is minimized to reduce the potential for particulate $\mathrm{P}$ loss via erosion and placement is sufficiently above the groundwater table. Infiltrating rainfall events tend to translocate surface applied $\mathrm{P}$ into the soil

A.S. Collick, T.L. Veith, P.J.A. Kleinman, A.R. Buda, and R.B. Bryant, USDA-ARS, Pasture Systems and Watershed Management Research Unit, University Park, PA 16802; D.R. Fuka and Z.M. Easton, Virginia Tech, Dep. Biological Systems Engineering, Blacksburg, VA 24061; J.L. Weld, Pennsylvania State Univ., Dep. Ecosystem Science and Management, University Park, PA 16802; P.A. Vadas, USDA-ARS, Dairy Forage Research Center, Madison, WI 53706; M.J. White and R.D. Harmel, USDA-ARS, Grassland, Soil and Water Research Laboratory, Temple, TX 76502. Mention of a model or trademark does not imply endorsement by authors or their institutions. USDA, Virginia Tech, and Pennsylvania State University are equal opportunity providers and employers. Assigned to Associate Editor Cole Green.

Abbreviations: 4R, four factors of effective nutrient management and stewardship: Right placement, Right timing, Right rate, Right form; APEX, Agricultural Policy Environmental EXtender; HRU, hydrologic response unit; PSP, user-defined P availability parameter for SWAT; TI, topographic index; TP, total phosphorus; SWAT, Soil Water Assessment Tool; WEP, water extractable phosphorus; WEP, inorganic water extractable phosphorus; $\mathrm{WEP}_{\mathrm{O}^{\prime}}$ organic water extractable phosphorus. 
where it is subject to sorption and desorption equilibria, whereas events with substantial runoff fractions tend to wash off surface applied sources of P (Coover, 2012; Kleinman et al., 2004). High concentrations of water soluble $\mathrm{P}$ from unincorporated surface applications can be transported overland during intense or longduration runoff events (Pote et al., 2011; Vadas et al., 2004). Indeed, the rainfall-to-runoff ratio has been key to predicting the loss of surface applied P via runoff water (Radcliffe et al., 2009; Vadas et al., 2004).

Kleinman and Sharpley (2003) illustrated the impact of application timing, with respect to precipitation events, on surface runoff concentrations. The highest concentrations of $\mathrm{P}$ in runoff are typically found in runoff events occurring immediately after surficial P application (Pote et al., 2011). However, surface-applied manure can continue to contribute to P concentrations in surface runoff months after application (Harmel et al., 2009; Vadas et al., 2007b).

Due to the interdependence among the $4 \mathrm{R}$ factors, soluble $\mathrm{P}$ magnitude and solubility within the source media become indicators of $\mathrm{P}$ in runoff when application placement and timing are controlled (Edwards and Daniel, 1993; Kleinman et al., 2007; Radcliffe et al., 2009; Vadas et al., 2007a, 2013). For example, Geìrard-Marchant et al. (2005) found mobile dissolved P in surface dairy, poultry, and swine manure decays exponentially with time after application. Accordingly, they developed overland loss equations based on first-and second-order kinetics to improve $\mathrm{P}$ transport and loss predictions in overland water quality models. Elliott et al. (2006) developed equations relating the water extractable P (WEP) content of fertilizers and manures to dissolved $\mathrm{P}$ in runoff, from which coefficients were determined for site evaluation indices.

Despite an abundance of empirical observations and mathematical relationships correlating agricultural management of $P$ sources to minimal $P$ in runoff, few of these advances have been incorporated into watershed models (Radcliffe et al., 2009, 2015; Vadas et al., 2013). Model routines that describe dissolved $\mathrm{P}$ source contribution to runoff typically rely on basic transfer equations that relate concentrations in a source to concentrations in runoff (Radcliffe et al., 2009; Vadas et al., 2013). For soil $P$ sources, an extraction coefficient is generally used to convert certain pools of $\mathrm{P}$ in soil within an effective depth of interaction (typically the upper few cm; Sharpley, 1985) into concentrations of $\mathrm{P}$ in runoff (Sharpley et al., 2002; Vadas et al., 2013).

Sedorovich et al. (2007) improved runoff P loss predictions of the Integrated Farming Systems Model (IFSM) by incorporating the equations of Vadas et al. (2007a). Rossi et al. (2012) incorporated the nonlinear Langmuir model into SWAT2005 to account for high soluble P conditions (e.g., water treatment residuals), with promising results. Sen et al. (2012) compared watershed-level output predictions of dissolved and total P between a 2008 version of SWAT (Neitsch et al., 2011) with the empirical equations of Vadas et al. (2007a). Results supported the continued upgrade of empirically based $P$ routines in SWAT and similar watershed models. More recently, Vadas et al. (2012) developed the Annual Phosphorus Loss Equation model, which uses empirical relationships to simulate $\mathrm{P}$ fate and transport in and from soils and is thought to be sensitive to the $4 \mathrm{R}$ management factors.
This paper documents incorporation of daily $\mathrm{P}$ equations of Vadas et al. (2007a, 2012) into the most current public release of SWAT at the time of this study (SWAT2012 version 586), and into a variation of the same SWAT2012 version 586 code that incorporates variable source area hydrology through topographic wetness classes in the input files (TopoSWAT; Easton et al., 2008, 2011). Phosphorus terminology throughout the manuscript follows Pierzynski (2000).

Edaphic and applied P simulations in conventional SWAT and TopoSWAT were assessed under field-level, historical management conditions for both the standard and new $\mathrm{P}$ routines. Sensitivities of these two incorporated $\mathrm{P}$ routines were evaluated under controlled $\mathrm{P}$ applications representative of $4 \mathrm{R}$ nutrient management stewardship.

\section{Materials and Methods}

\section{Mattern Study Watershed, Pennsylvania}

The Mattern watershed, within the Mahantango Creek watershed, in the Valley and Ridge Physiographic Province of Pennsylvania was selected (Fig. 1). A long history of hydrologic and water quality monitoring by the USDA-ARS (Bryant et al., 2011), soil profile data, and collaboration with farmers in the watershed have enabled rigorous model parameter initialization and testing with an array of watershed, hillslope, and field scale datasets (Collick et al., 2015). The 11-ha Mattern watershed exhibits well-documented runoff generation processes characterized by variable source area hydrology (Buda et al., 2009a) and $P$ transport in surface runoff (Buda et al., 2009b; Kleinman et al., 2006). Mean precipitation is approximately $1100 \mathrm{~mm}$. Mean monthly temperatures range from $-4^{\circ} \mathrm{C}$ in January to $21^{\circ} \mathrm{C}$ in July.

The Mattern watershed is dominated in upslope areas by the well-drained Berks soil (loamy-skeletal, mixed, active, mesic Typic Dystrudept), with slopes ranging from 0.8 to $31.7 \%$. The Berks soil lacks subsoil restrictive features that would slow infiltration. In contrast, a somewhat poorly-drained Albrights soil (fine-loamy, mixed, semiactive, mesic Aquic Fragiudalf) occupies lower landscape positions. The Albrights soil is underlain by a fragipan at a depth of approximately $60 \mathrm{~cm}$ that has been shown to impede water transmission. Previous research by Buda et al. (2009a) indicated that as much as $80 \%$ of hillslope runoff was generated from the Albrights soil, predominantly by "saturation excess runoff” during prolonged periods of soil saturation.

Land use in the Mattern watershed is currently dominated by row crop agriculture, except in the immediate proximity of the stream, which is managed as a vegetated buffer. Upslope, five fields (0.9-1.9 ha), three full and two partial, are contained within the watershed boundaries and are under a typical Pennsylvanian row crop rotation of corn, soybean, small grain, and grass or alfalfa hay. Hay is usually grown for three to five consecutive years after two years of corn, corn-soybean, or small grains.

\section{Modifications of SWAT to Simulate Site Hydrology and Phosphorus Cycling}

\section{Conventional SWAT}

The SWAT model (Arnold et al., 2012; Neitsch et al., 2011) is a widely used watershed-scale model with multiple versions 

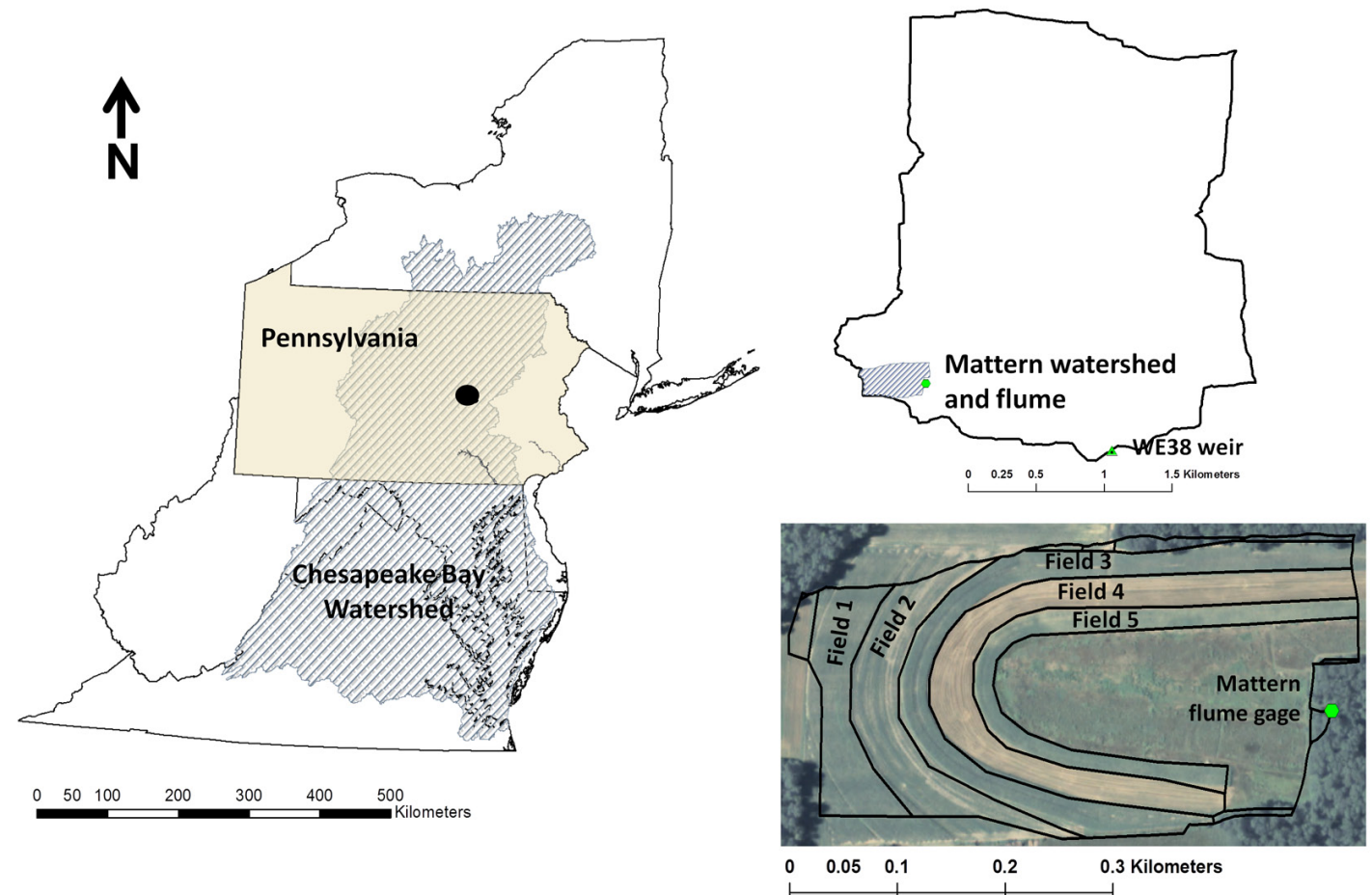

Fig. 1. Location of the study watershed in the mid-Atlantic United States, with general location of the Mattern watershed within the USDA-ARS long-term WE-38 experimental watershed (upper right inset) and layout of fields and gauge within the Mattern watershed (lower right inset).

that simulates water quantity and quality impacts of land use, management, and climate over a continuous time period across varying scales (field to subbasin to river basin). The smallest unique spatial unit in SWAT is the hydrologic response unit (HRU), which is the spatial intersection of land use, soil, and slope class geospatial layers that are provided as input by the user. Within each HRU, SWAT simulates daily water movement vertically in the soil profile including evapotranspiration, uptake by roots, upward movement from shallow aquifer to vadose zone, and downward movement into a shallow or deep groundwater aquifer.

The public release of the conventional SWAT model at the time of this study (SWAT2012 revision 586) routes lateral flow from HRU to the corresponding subbasin stream; there is no horizontal routing between neighboring HRUs. While this is a simplification of the natural system, it has been one of necessity to enable the multitude of other capabilities that researchers need (Arnold et al., 2010). Maintaining a denser routing network in the horizontal plane in addition to the current routing in the vertical and temporal dimensions substantially increases the programming and computational complexities of the software. Furthermore, the denser network becomes inefficient without correspondingly detailed input data and pushes the feasible limits of project setup for most "what if" problem-solving applications of SWAT.

\section{TopoSWAT}

We used a variation of conventional SWAT called TopoSWAT (Fuka, 2013) to improve representation of hydrology at the subfield level. Conventional SWAT and TopoSWAT use the same land use layer. In this study, that land use layer was defined by spatially distinct, subfield level HRUs and their corresponding multiyear historical management data.
TopoSWAT then uses an ArcMap Toolbox (ESRI, 2012) module to replace the conventional SWAT spatial input layers of slope class and soils with a single spatial layer that represents topographic properties relevant to hydrology (Beven and Kirkby, 1979). Following Easton et al. (2008), a topographic wetness index (TI) layer is generated from the slope and soil layers as a function of upstream drainage area and local slope. The TI layer consists of ten classes ranging from 1 (driest and least prone to saturate) to 10 (most frequently saturated). The area of each HRU is then defined by the intersection of land use and TI class. Soil properties, including bulk density, soil texture, hydraulic conductivity and curve number, are then distributed across these TI classes.

Conventional SWAT does not route lateral flow directly from HRU to HRU, thus toe-slope and floodplain regions closer to the river do not receive the expected direct lateral flow from upslope contributing areas (Bonumá et al., 2012). Accordingly, the movement of water and nutrients is impacted at the field and subfield scales, particularly in areas prone to saturation excess or to retention ponding where overland flow accumulates and slowly infiltrates. TopoSWAT addresses this flow limitation by redistributing vadose zone water among TI classes within a given land use polygon via the SWAT auto irrigation routine. Incorporation of the irrigation routine allows the reach to act as an aquifer storage pool that increases and decreases water table depth of HRUs based on reach flow rates (Collick et al., 2015). On a daily basis the auto irrigation routine transfers water from the reach to HRUs with high TI values while soil water is drained from HRUs with lower TI values and added to the reach. Using spatially maintained HRUs defined at the subfield level, Collick et al. (2015) confirmed superior representation $(\mathrm{NSE}=0.7)$ of variable source area hydrology in TopoSWAT, as compared with conventional SWAT (NSE $=0.6$ ), as well as improved prediction 
of $\mathrm{P}$ loss in runoff at $\mathrm{HRU}$ and watershed scales by incorporating this intra-subbasin transfer. Cumulative soluble P more closely followed the cumulative monitored P losses.

\section{Alternative Phosphorus Routines for SWAT}

We developed new P routines for SWAT2012 by incorporating daily P loss equations from Vadas et al. (2007a, 2012) into the conventional SWAT (revision 586) and TopoSWAT code. Modifications were incorporated into the 15 subroutines available in the SWAT management operations, including grazing, auto- and continuous fertilization, and fertilizer applications. These modifications are referred to as "new $\mathrm{P}$ routines" in this paper to distinguish them from the standard $\mathrm{P}$ routines in SWAT2012 version 586. The new P routines incorporate two basic process changes: i) surface pool additions for manure $P$ and ii) dynamic partitioning among soil $\mathrm{P}$ pools. The dynamic portioning has been incorporated in some research versions of conventional SWAT previously, but not in conjunction with the manure P component.

\section{Manure Phosphorus Revisions}

In the conventional version of SWAT, when manure is applied to the soil surface without incorporation, the model automatically integrates the manure into the top $10 \mathrm{~mm}$ of the soil and allows the soil nutrient cycling routines to determine the fate of the manure P. The new P routine instead simulates a discrete layer of manure on the soil surface. No changes are made for commercial fertilizer or other sources of $\mathrm{P}$ such as plant residue.

The new $\mathrm{P}$ routines, based on the equations of Vadas et al. (2007a, 2012), partition surface-applied manure into four interactive pools: water extractable inorganic $\mathrm{P}(\mathrm{WEP})$, water extractable organic $\mathrm{P}\left(\mathrm{WEP}_{\mathrm{O}}\right)$, solid-phase inorganic $\mathrm{P}$, and solid-phase organic $\mathrm{P}$. These four pools sum together to represent manure total $\mathrm{P}(\mathrm{TP})$ at any given time step. Manure $\mathrm{WEP}_{\mathrm{I}}$ and $\mathrm{WEP}_{\mathrm{O}}$ pools represent $P$ that can be leached from manure by rain, while solid-phase inorganic and organic $\mathrm{P}$ are not leachable by rain but are transformed to $\mathrm{WEP}_{\mathrm{I}}$ or $\mathrm{WEP}_{\mathrm{O}}$ as manure decomposes and manure $\mathrm{P}$ mineralizes. If manure with dry matter content less than $15 \%$ is applied, the model assumes manure solids remaining on the surface cover $50 \%$ of the application area and that the manure liquid immediately infiltrates into soil to add $60 \%$ of the manure TP to the soil P pools. The model further assumes that $60 \%$ of this infiltrated slurry P remains in the top $2 \mathrm{~cm}$ of soil while the remaining $40 \%$ infiltrates deeper into the vadose zone (Vadas et al., 2005).

The manure $\mathrm{P}$ routine simulates decomposition of manure dry matter on a daily basis as a function of air temperature, precipitation, manure moisture content, and area covered by manure. This process represents natural bioturbation that slowly mixes manure into soil. The model keeps track of dry matter for each manure application and adds existing manure dry matter to determine total dry matter for the present day being simulated. The area of manure coverage decreases at the same rate as dry matter decomposition. Simulating decomposition of manure dry matter and cover enables the simulated interaction of rain with manure, which in turn predicts $P$ leaching from manure during a storm.

When rain falls, manure $\mathrm{WEP}_{\mathrm{I}}$ and $\mathrm{WEP}_{\mathrm{O}}$ are leached from manure as a function of the ratio between water and manure dry matter $\left(\mathrm{cm}^{3} \mathrm{~g}^{-1}\right)$. The ratio is calculated as a function of both manure mass and area covered. If runoff occurs, some leached manure $\mathrm{P}$ is transferred to runoff, with the concentration of dissolved $\mathrm{P}$ in runoff $\left(\mathrm{mg} \mathrm{L}^{-1}\right)$ calculated as a nonlinear function of the runoff to precipitation ratio. A mass of $\mathrm{P}$ in runoff $(\mathrm{kg})$ is calculated by multiplying runoff $\mathrm{P}$ concentrations by runoff volumes. Manure $\mathrm{P}$ that infiltrates into soil is calculated as the difference between $\mathrm{P}$ leached from manure and $\mathrm{P}$ transported in runoff. For infiltrated manure P, $80 \%$ is added to soil pools in the top $2 \mathrm{~cm}$ of soil, with $20 \%$ infiltrating deeper.

\section{Soil Phosphorus Cycling Revisions}

Both conventional SWAT and TopoSWAT simulate three inorganic soil $\mathrm{P}$ pools to represent soil inorganic $\mathrm{P}$ cycling: solution, active, and stable P. They apply user-defined parameters and fixed coefficients to initialize the quantity of these $\mathrm{P}$ pools and the rate of $\mathrm{P}$ transfer between them. In particular, solution $\mathrm{P}$ is a user-defined parameter, active $\mathrm{P}$ is initialized based on solution $\mathrm{P}$ and a $\mathrm{P}$ availability parameter called PSP, and stable $\mathrm{P}$ is initialized at four times the size of active P. PSP is used to calculate the amount of $\mathrm{P}$ that should be transferred between inorganic pools when they become out of equilibrium, such as when $\mathrm{P}$ is applied to soil via chemical or manure fertilization, or is removed from the soil through plant uptake or movement with water. In conventional SWAT, PSP is a user-defined parameter that can be modified or left at a default value of 0.4 (Neitsch et al., 2011). Regardless, PSP in conventional SWAT remains static throughout the simulation run and results in the stable $\mathrm{P}$ pool maintaining itself as fourfold the size of the active $P$ pool. In contrast, the new $P$ routines incorporate a dynamic PSP, which is recalculated at the beginning of each simulation year based on equations from Vadas et al. (2012) and can range from 0.05 to 0.9 . The soil $P$ routines were also modified to simulate daily P transfers between the active and solution P pools as proposed by Vadas et al. (2006). These changes create a more dynamic relationship among the solution, active, and stable $P$ pools than found in the publically released version of conventional SWAT. These dynamic rate factors change as needed throughout the simulation, to maintain equilibrium between the solution and active $\mathrm{P}$ pools.

\section{Input Data for Model Performance Assessments}

To apply the conventional SWAT and TopoSWAT models as intended by their developers, different soil layers were used for each of the models. All other spatial layers and input data were identical between the models. These input data and their sources are described below.

The conventional SWAT model used the USDA-NRCS Soil Survey Geographic (SSURGO) Database. Required soil attributes were gathered from the SSURGO database established for SWAT (Soil Survey Staff, 2015), and the soil spatial layer and its lookup table were formatted for use in SWAT. For TopoSWAT, required soil properties were extracted from the Food and Agriculture Organization Digital Soil Map of the World (FAOUNESCO, 2007), as described by Easton et al. (2008).

The watershed boundary and drainage network were delineated from a 10-m DEM resampled from a 0.5-m LiDAR image and corroborated by observed flow and wetness zones from long-term research technicians in the watershed. Using the DEM, two slope classes $(0-12 \%$ and $>12 \%)$ were defined 
for use in conventional SWAT. For TopoSWAT, a topographic wetness index (TI) layer was generated from the slope and FAO soil layers as a function of upstream drainage area and local slope (Collick et al., 2015).

For both the conventional SWAT and TopoSWAT models, the land use layer was created explicitly to maintain spatially distinct HRUs at the subfield level using the method of Ghebremichael et al. $(2008,2010)$, Veith et al. $(2005,2008)$, and Collick et al. (2015). Management for each field was previously recorded in the 12-yr historical management database created from farmer interviews from 1999 to 2010 (detailed in Collick et al., 2015). Although the Mattern watershed consists of only five row-cropped fields, no two fields are historically managed identically or in strict rotations. To provide analytical control in evaluating sensitivity of the $P$ routines, management operations were standardized into two rotations within the watershed. These rotations were based as closely as possible on the 12-yr historical management using specifically the years with measured hydrology data, or the years of evaluation (2006-2010). Rotations were staggered across fields so that no two fields started the same rotation cycle on the same year (Table 1). Crops included corn, soybeans, small grains (most commonly winter barley), and hay (clover or timothy grass). Planting and harvesting practices followed traditional practices. For the conventional SWAT and TopoSWAT models, management was then specified for each field, using date-specific operations, throughout the entire simulation period.

Five-minute interval datasets of precipitation, minimum and maximum temperatures, relative humidity, and wind speed from 1986 to 2010 were collected from the USDA-ARS weather station within the watershed and condensed to daily averages in SWAT format. Continuous discharge and water quality variables (dissolved reactive $\mathrm{P}, \mathrm{TP}$, and sediment) from the Mattern outlet were collected from 2006 through 2010 and summarized into daily intervals.

\section{Hydrologic and Phosphorus Routines under Historical Management Conditions}

For each of the conventional SWAT and TopoSWAT models, we evaluated the performance of the standard and new $\mathrm{P}$ routines in the Mattern watershed. Cumulative P loads from nondaily, but frequent, stream samplings were used to initialize the solution $\mathrm{P}$ in the soil $\mathrm{P}$ pools. Solution soil $\mathrm{P}$ values were set at $50 \mathrm{mg} \mathrm{kg}^{-1}$ for conventional SWAT initializations of both P routines and at 35 and $20 \mathrm{mg} \mathrm{kg}^{-1}$ for TopoSWAT initializations of standard and new $\mathrm{P}$ routines, respectively. This was the only calibration parameter adjusted between the conventional SWAT and TopoSWAT models when testing the standard and new $\mathrm{P}$ routines.

\section{Simulating Phosphorus Application Timing, Rate, Method, and Form}

To the extent possible, the impact of each of the $4 \mathrm{R}$ factors was evaluated independently, while controlling for the other factors. Certainly, we recognize that the $4 \mathrm{R}$ factors are not independent in their impacts. However, it was not feasible to compare the response of the standard and new $\mathrm{P}$ routines to all possible combinations of variations in the $4 \mathrm{R}$ factors of nutrient management. Therefore, we limited the focus of our analysis and discussion to the particular $4 \mathrm{R}$ factor variations that we felt would be most informative in understanding and improving manure management in northeastern United States. All comparisons were made between the standard and new $\mathrm{P}$ routines in conventional SWAT and TopoSWAT (a total of four "treatments" or modeling combinations).

Impact of application timing was evaluated through near term trends in "incidental transfer" or "wash off" of manure P (e.g., Preedy et al., 2001; Buda et al., 2013). Typical storm events were selected from spring, fall, and winter of each year during the 2006 to 2010 monitoring period. Broadcast, non-incorporated application of dairy manure was simulated 1,5 , and $10 \mathrm{~d}$ before each selected storm event at a rate of $35 \mathrm{~kg}$ TP ha $\left(31 \mathrm{lbs} \mathrm{TP} \mathrm{ac}{ }^{-1}\right)$. This is a common P-based application rate for Pennsylvania, assuming a typical dairy manure with $7.8 \%$ dry matter and $620 \mathrm{mg} \mathrm{TP} \mathrm{L}^{-1}$ (5.2 lbs TP per $1000 \mathrm{gal}$ ) (Penn. State Univ. Agricultural Analytical Services Laboratory, unpublished data, 2012).

Manure application rate was evaluated by simulating broadcast manure application, without incorporation, at 35 and $52 \mathrm{~kg} \mathrm{TP} \mathrm{ha}^{-1}$ (31 and $46 \mathrm{lbs}$ TP ac${ }^{-1}$ ) $1 \mathrm{~d}$ before a storm in spring, fall, and winter each year, as described for application timing. These application rates are equivalent to 56,000 and $84,000 \mathrm{~L} \mathrm{ha}^{-1}$ (6000 and $9000 \mathrm{gal} \mathrm{ac}^{-1}$ ) of dairy slurry with $7.8 \%$ dry matter. Total cumulative losses of $\mathrm{P}$ in runoff were estimated for individual fields in the Mattern watershed over the 2-wk period following application of each storm.

Manure application method effects were evaluated by simulating the broadcast application of dairy manure $1 \mathrm{~d}$ before select storms at a rate of $35 \mathrm{~kg} \mathrm{TP} \mathrm{ha}^{-1}\left(31 \mathrm{lbs} \mathrm{TP} \mathrm{ac}{ }^{-1}\right)$. Manure was either left unincorporated on the soil surface, or incorporated immediately after application by disk at a disruption depth of $10 \mathrm{~cm}$ and a mixing efficiency of $85 \%$ on average.

Applied P form was assessed by simulating the broadcast application of dairy slurry or mineral fertilizer (i.e., diammonium phosphate) to row crop fields requiring nutrient amendment. For both manure and mineral fertilizer, a fixed rate application of $35 \mathrm{~kg}$ TP ha-1 (31 lbs TP ac-1) was simulated.

Table 1. Historical crop rotations for five fields (Fig. 1) during the analysis period on the Mattern watershed.

\begin{tabular}{lccccc}
\hline Year & Field $\mathbf{1}$ & Field $\mathbf{2}$ & Field $\mathbf{3}$ & Field $\mathbf{4}$ & Field $\mathbf{5}$ \\
\hline 2006 & Corn to winter barley & Oats to clover & Corn to timothy hay & Timothy hay & Winter barley to fallow \\
2007 & Winter barley to fallow & Clover & Timothy hay & Timothy hay & Corn \\
2008 & Soybeans & Clover & Timothy hay & Corn & Corn to winter barley \\
2009 & Corn to winter barley & Clover & Corn & Oats to winter barley & Winter barley to fallow \\
2010 & Winter barley to fallow & Corn & Corn to timothy hay & Winter barley to timothy hay & Corn \\
\hline
\end{tabular}




\section{Data Analysis}

Results from the four modeling treatments, (one of either standard P routines or new $\mathrm{P}$ routines coupled with one of either conventional SWAT or TopoSWAT), under the historical management were evaluated via hydrograph, scatter plot, and calculation of the Nash-Sutcliffe correlation coefficient (Nash and Sutcliffe, 1970). In addition, average residuals between measured and predicted variables were explored visually to identify trends and isolate events in which differences were amplified. Monitored flows were used to corroborate conventional SWAT and TopoSWAT on a daily time step, whereas cumulative and event-based $\mathrm{P}$ loads in runoff observed from long-term watershed monitoring were used to assess the effects of different $\mathrm{P}$ routines on model performance.

\section{Results and Discussion}

\section{Conventional SWAT and TopoSWAT Simulation of Historical Field Management \\ Hydrology}

Both conventional SWAT and TopoSWAT models provided satisfactory representation of hydrology (Fig. 2a), based on Nash-Sutcliffe values for daily flow at the watershed outlet (Nash-Sutcliffe coefficient of 0.5) (Moriasi et al., 2007). However, both versions of SWAT tended to underestimate flow for larger events $\left(>0.01 \mathrm{~m}^{3} \mathrm{~s}^{-1}\right)$, as revealed by graphing the residuals (Fig. 2b). This was particularly evident for the event on 28 June 2006, which involved $3 \mathrm{~d}$ of heavy rainfall and elevated discharge that exceeded model predictions. The 28 June 2006 storm had a disproportionate effect on the performance of the two models, such that, by correcting for the error associated with this storm, the Nash-Sutcliffe coefficient for discharge increased to 0.7 for both conventional SWAT and TopoSWAT.

In addition to underpredicting large events, conventional SWAT tended to overpredict flow for the smallest events, even when watershed discharge was not observed, whereas TopoSWAT more closely matched the small events (Fig. 2a). Surprisingly, addition of the new $P$ routines actually improved the representation of hydrology for both conventional SWAT and TopoSWAT (Nash-Sutcliffe coefficient of greater than 0.5 ). It is possible that by representing the manure layer above the soil surface, the new $P$ routines allowed for better representation of the interaction of rainfall with soil surface. When expressed on a cumulative basis (Fig. 2b), measured flows were best predicted with TopoSWAT, confirming the findings of Collick et al. (2015) that TopoSWAT more accurately represents the variable source area hydrology of this region. Conventional SWAT overpredicted cumulative flow, reflecting the erroneous and overprediction of flows with small rainfall events (Fig. 2c).

\section{Phosphorus Cycling Among Manure, Runoff, and Soil}

With the standard P routines, both conventional SWAT and TopoSWAT systematically under predicted cumulative losses of soluble $\mathrm{P}$ in runoff, with total cumulative loss across the period of analysis estimated by both models as $0.5 \mathrm{~kg} \mathrm{ha}^{-1}$ less than monitored data (Fig. 3). Notably, cumulative soluble P loss in runoff predicted by conventional SWAT tended to increase in a
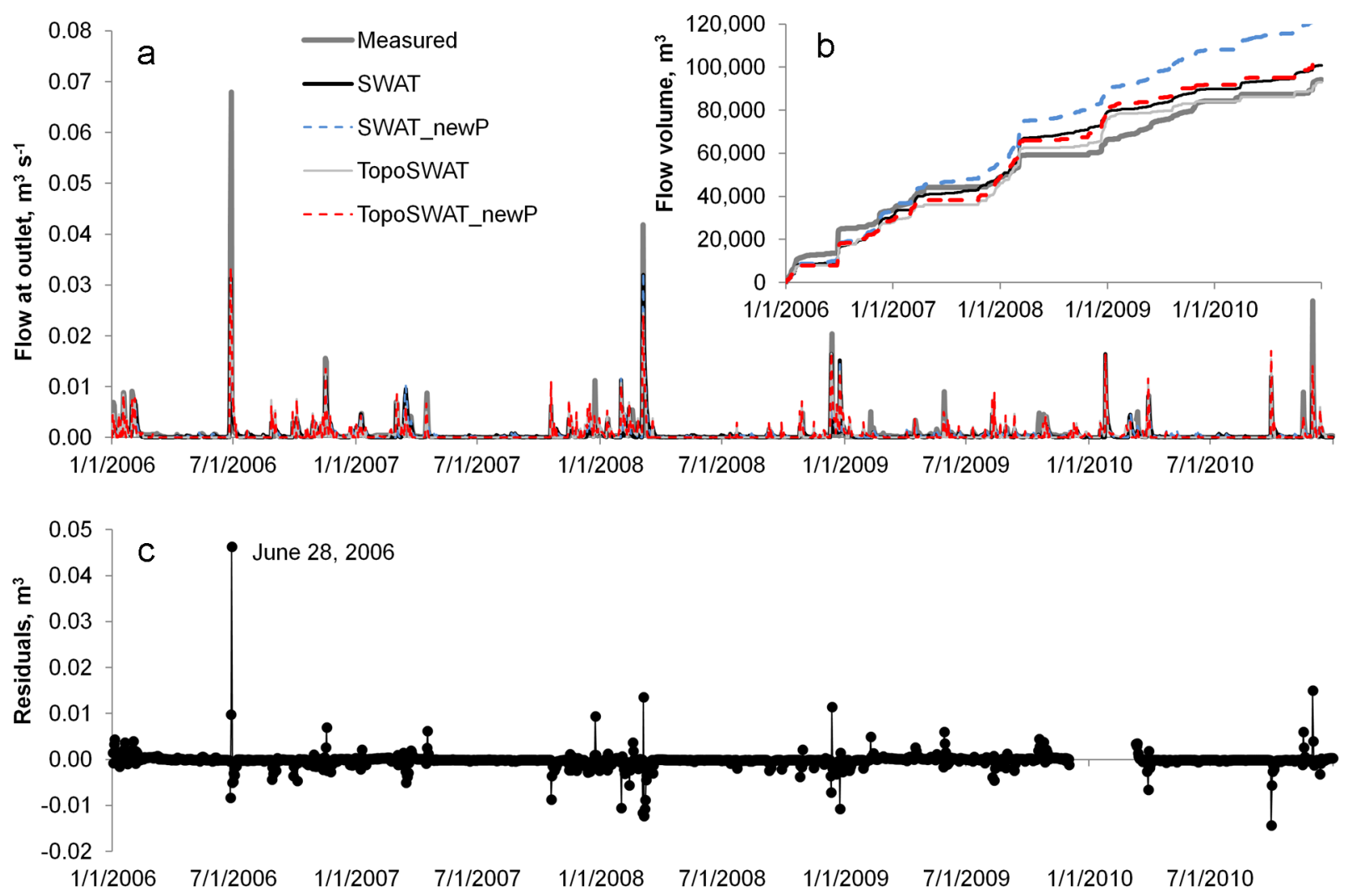

Fig. 2. Comparison of daily streamflow (a) and cumulative streamflow volume (inset, b) at the Mattern watershed outlet for actual management between standard and new P routines in conventional Soil and Water Assessment Tool (SWAT) and a topographically driven variation (TopoSWAT) (a). Daily residuals show the difference between simulated flow, averaged across all four models, and measured flow (c). 
punctuated fashion, whereas cumulative soluble P loss predicted by TopoSWAT exhibited a more steady change, consistent with the pattern of change observed with monitoring data. No combination of the conventional SWAT or TopoSWAT models, with either standard or new P routines, matched measured losses for the large storm on 28 June 2006, as error in predicting the hydrology for this event (described above) confounded predictions of soluble P loss in runoff.

When the standard $\mathrm{P}$ routines were replaced with the new $P$ routines, prediction of soluble $\mathrm{P}$ losses deviated between conventional SWAT and TopoSWAT, even though the patterns of loss were consistent over time (Fig. 3). Results suggest that the new $P$ routines more accurately illustrate the effects of systematic changes in manure management practices on $P$ runoff losses than the standard P routines, particularly when incorporated into TopoSWAT.

Cumulative soluble P losses predicted by conventional SWAT increased sufficiently to match the measured losses, demonstrating the sensitivity of the new $\mathrm{P}$ routines to surface application of manure WEP. However, an increase in soluble P loss was not observed during the 26 June 2006 storm when manure was applied 2 mo before the storm. Therefore, the correspondence between cumulative soluble P loss predicted by conventional SWAT with the new P routines and measured losses at the end of the period of assessment are coincidental since they did not track similar patterns over the entire period and resulted in predictions of soluble P loss in runoff that were lower than observed losses for most of the assessment period.

Results for both conventional SWAT and TopoSWAT illustrate the potential for the new $P$ routines to inflate the effect of manure application on soluble P losses. Such inflation was noted, in particular, when manure was applied to much of the watershed within 1 wk before the major storm events on 7 Mar. 2008 and 29-30 Oct. 2008. Cumulative soluble P losses predicted by the new P routines in both conventional SWAT and TopoSWAT increased by nearly $0.04 \mathrm{~kg} \mathrm{ha}^{-1}$ during each of these storms. When the new P routines were added to TopoSWAT, which is more sensitive to saturation excess runoff than is conventional SWAT, cumulative soluble P losses were substantially overestimated, with extremely large increases occurring in the periods of March and October in 2008 when manure was applied around the time of significant runoff events.

\section{Simulating the Effects of Phosphorus Application Timing, Rate, and Form \\ Timing of Manure Application (1, 5, or $10 \mathrm{~d}$ Before a Storm)}

Stark differences are apparent between the standard and new $\mathrm{P}$ routines when the effects of the timing of broadcast manure application relative to runoff generating rainfall events (Fig. 4a) were simulated. Most notably, the standard P routines were insensitive to recent applications of manure, as illustrated through similar trends in soluble P losses in runoff for events occurring before and after manure application (Fig. 4b). Indeed, losses of $\mathrm{P}$ in runoff with the standard $\mathrm{P}$ routines were several orders of magnitude less than those observed with the new $\mathrm{P}$ routines (Fig. $4 \mathrm{c}$ ).

The new $\mathrm{P}$ routines predicted dramatic differences in runoff P losses before and after manure application (Fig. 4c), consistent with empirical observations of applied P wash off

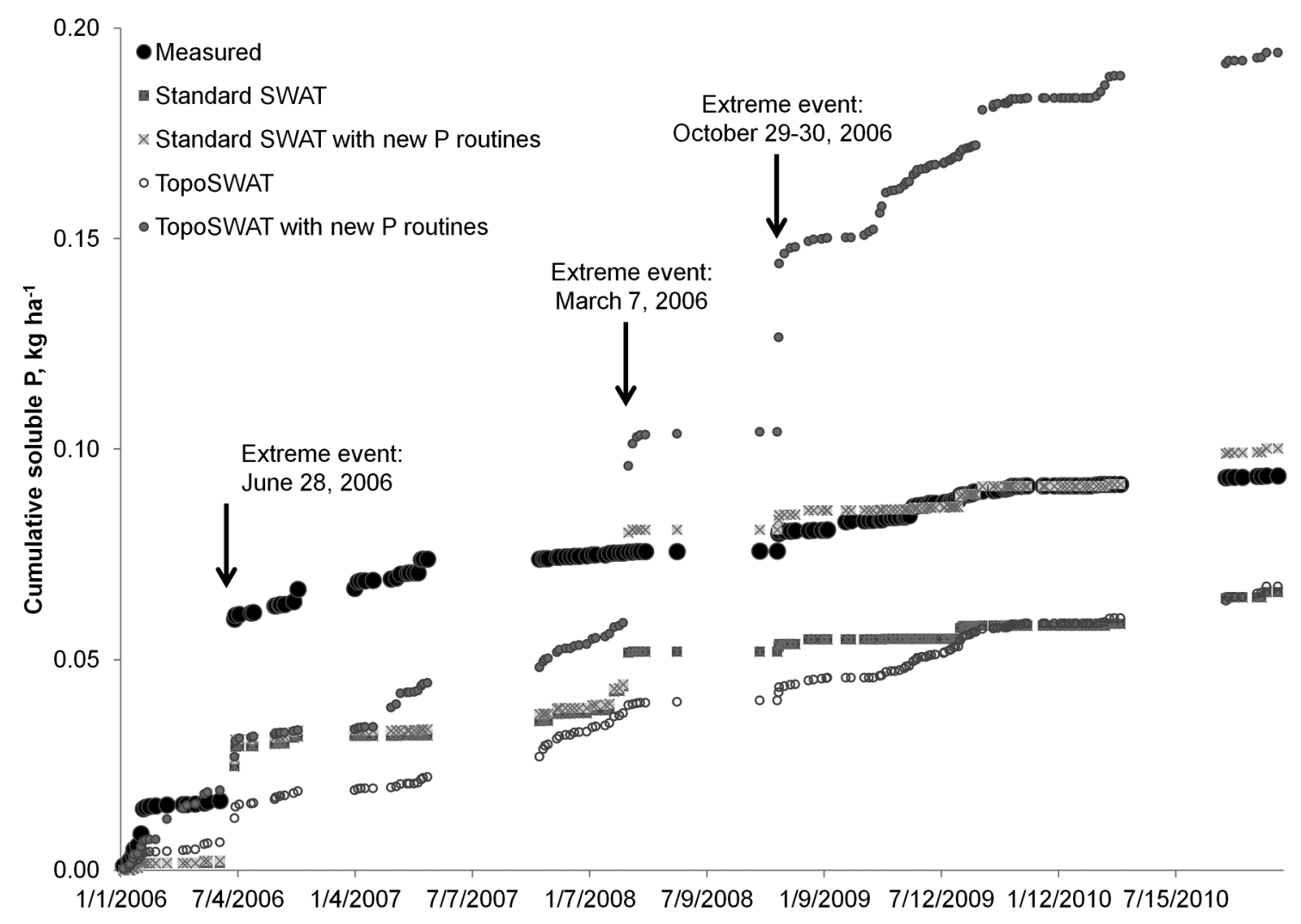

Fig. 3. Comparison of cumulative soluble $P$ at the Mattern watershed outlet for actual management between standard and new $P$ routines in conventional Soil and Water Assessment Tool (SWAT) and a topographically driven variation (TopoSWAT). 
found in the literature (e.g., Kleinman et al., 2009; Kleinman and Sharpley, 2003; Preedy et al., 2001). With the new P routines, losses of $\mathrm{P}$ were greatest when manure was broadcast $1 \mathrm{~d}$ before the runoff event and slightly diminished when manure was applied $5 \mathrm{~d}$ before the event. When manure was applied $2 \mathrm{~d}$ before a small event on January 23rd, followed by a major runoff event on January 31 st, the new $\mathrm{P}$ routines predicted small losses of soluble $\mathrm{P}$ in runoff from the small storm and then a further reduction in losses with the large event. These trends are consistent with the translocation of some P out of the applied manure and into the soil during the event on January 23rd (as well as removal of some P by runoff) and therefore a slightly depleted source of $\mathrm{P}$ at the onset of the event on January 31 st (Fig. 4b), as described by Kleinman et al. (2006) and Vadas et al. (2007b). Not surprisingly, the higher loads predicted with the new routines were consistent with those reported by Kleinman et al. (2006).

\section{Manure Application Rate (Low vs. High)}

Clear differences were apparent in the effects of manure application rate on TP loss between the standard and new P routines when integrated into TopoSWAT (Fig. 5). In all cases, average TP losses in runoff were larger for the new versus standard $\mathrm{P}$ routines (Fig. 5), reflecting the greater sensitivity of the new routines to $\mathrm{P}$ losses associated with broadcast manure application. Little to no difference in runoff TP losses was detected between the two manure application rates ( 35 and $\left.52 \mathrm{~kg} \mathrm{TP} \mathrm{ha}^{-1}\right)$ with the standard $\mathrm{P}$ routines. With the new $\mathrm{P}$ routines, the 1.5 -fold increase in manure $\mathrm{P}$ application resulted in a proportional difference in TP loss in runoff.

Among the fields, the greatest TP losses in runoff were associated with Field 4, which had both elevated runoff volumes and high soil P levels due to high levels of historical manure application. With the standard routines, the elevated losses of TP from Field 4 were primarily associated with the enrichment of runoff water from the solution $\mathrm{P}$ reservoir (driven by the $\mathrm{P}$ extraction coefficient in the model). With the new routines, the TP in runoff was driven by a combination of elevated solution $\mathrm{P}$ in the surface soil, as well as manure WEP. This coincidence in relative differences in TP losses between fields points to the potential for similar results to be driven by very different processes.

\section{Manure Application Method (Broadcast vs. Immediate Incorporation)}

Differences in the standard and new P routines were well expressed when different methods of application were simulated (Fig. 6). With the new routines, soluble P losses were exacerbated by surface application of dairy slurry in Mattern and decreased 2.5-fold with incorporation, whereas no such effect was observed with the standard P routines. Sediment P increased in both $\mathrm{P}$ routines with incorporation. This was as expected as this example represented an extreme case of soil disturbance to incorporate manure. However, with increasing requirements of immediate incorporation, more farmers
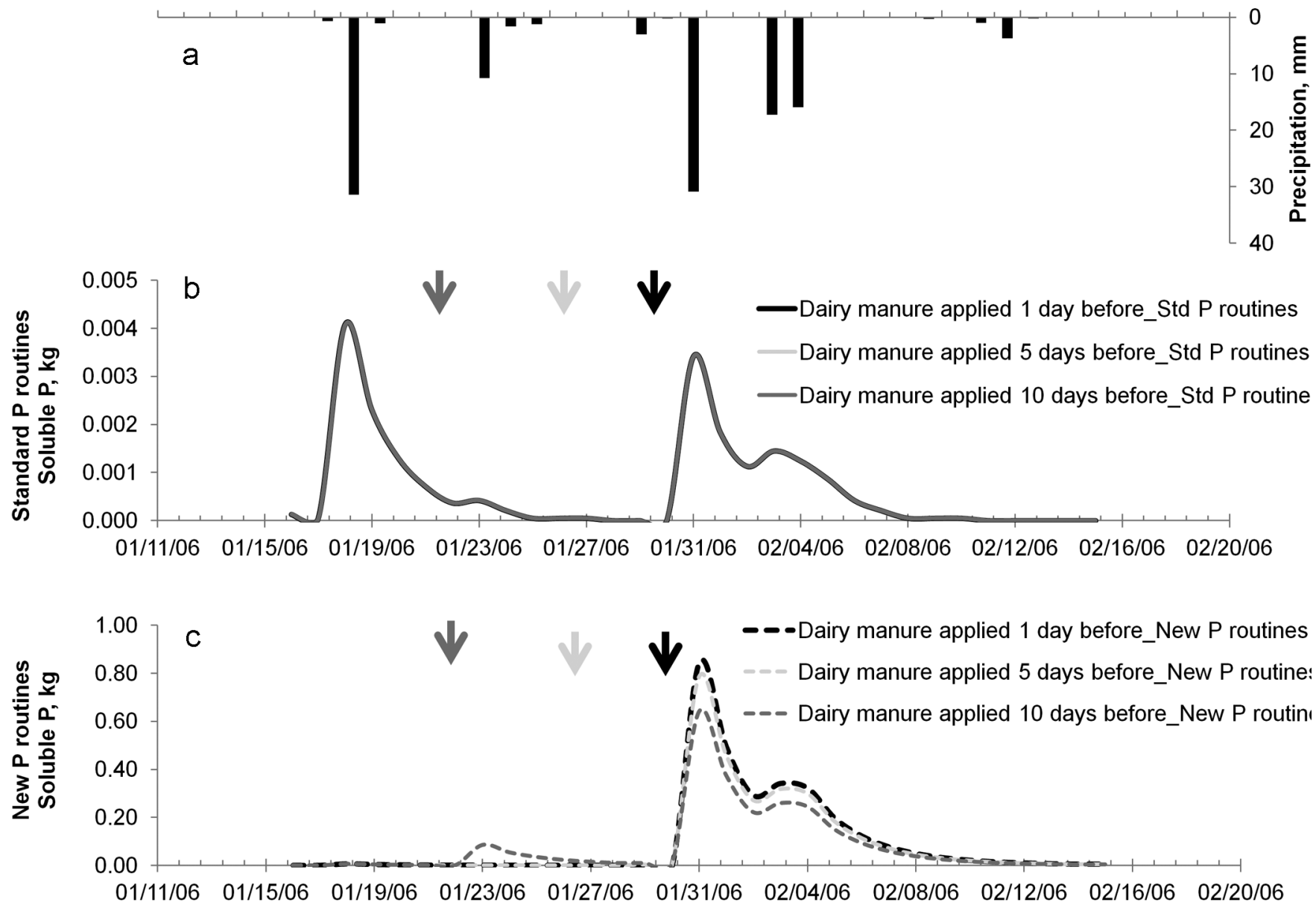

Fig. 4. Simulated effect of precipiation (a) and application timing of manure applied one day before a storm (black arrow), five days before a storm (light gray arrow), or ten days before a storm (dark gray arrow) on soluble P losses for standard (b) and new (c) P routines. 


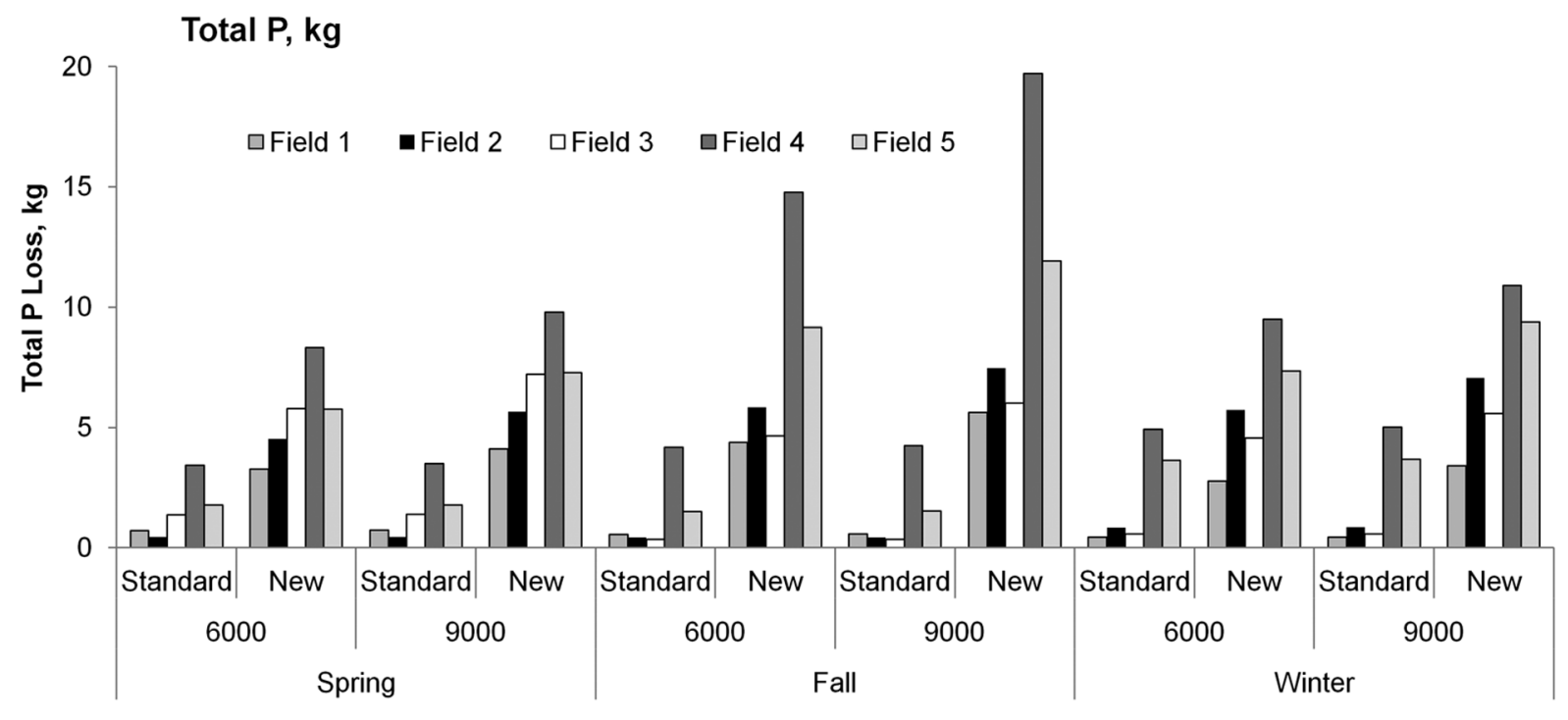

Fig. 5. Effect of application rate ( $35 \mathrm{vs.} 52 \mathrm{~kg} \mathrm{TP} \mathrm{ha}^{-1}$ ) in spring, fall, and winter on total P losses from five fields, between standard and new $\mathrm{P}$ routines.

are using existing equipment to incorporate manure whereas they otherwise would have only applied manure to the soil surface. This highlights the importance of the current and ongoing research efforts to create minimum disturbance, manure incorporation equipment that poses less of a time burden than a second-pass spread and till, minimal increase in cost over current equipment, and better physical incorporation with less disturbance.

\section{Phosphorus Form (Manure vs. Fertilizer)}

Commercial fertilizer applications were affected limitedly by the new P routines (Fig. 7a) since the focus of the modifications of $\mathrm{P}$ routines in SWAT was to improve simulation of manure. The standard $\mathrm{P}$ routines focus on the amount of $\mathrm{P}$ added to the soil without distinguishing between forms (Fig. 7b, dark circles). Because the new P routines incorporate the form of the fertilizer in addition to the amount of $\mathrm{P}$ from the fertilizer, wider variations in soluble P loading to the outlet were evident (Fig. 7c) despite a fixed rate application of $35 \mathrm{~kg} \mathrm{TP} \mathrm{ha}^{-1}$ across application form.

\section{Conclusions}

Representing the effects of conscientious nutrient management, through strategies such as the " $4 \mathrm{R}$ " factors, is key to the applicability of simulation models to assess impacts on water quality. While the empirical literature parsing the contribution of these sources to dissolved and particulate $P$ in runoff is robust, the modeling routines used to simulate the processes have not kept pace with empirical findings beyond the late 1980s, particularly for dissolved $\mathrm{P}$.

Incorporation of empirical equations accounting for the fate of manure P sources clearly improves the ability of SWAT to represent the consequences of applying $P$ to the soil surface, including the effect of timing of application relative to initial runoff events, rate of $\mathrm{P}$ application on overall $\mathrm{P}$ load, and method of

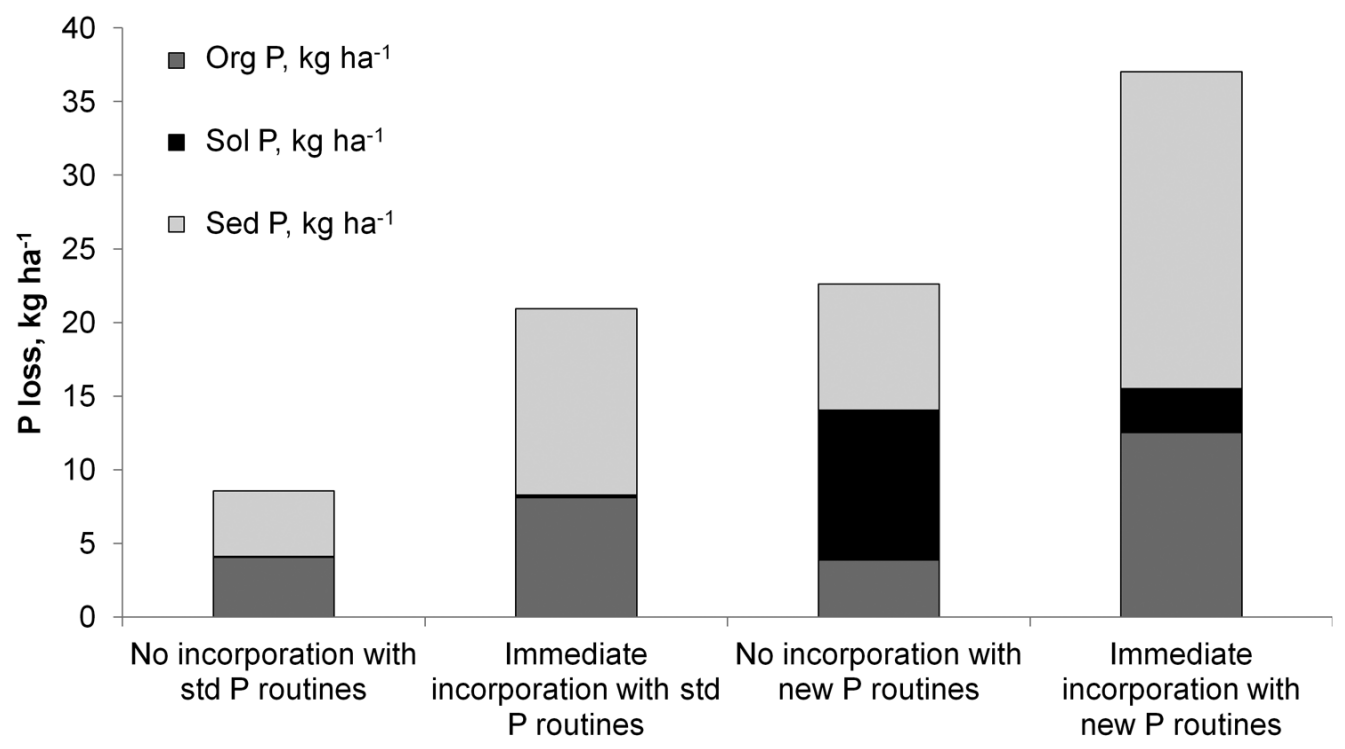

Fig. 6. Effect of manure application method (no incorporation vs. immediate) on the average annual P losses (organic, soluble, and particulate P), between standard and new $P$ routines. 
A.

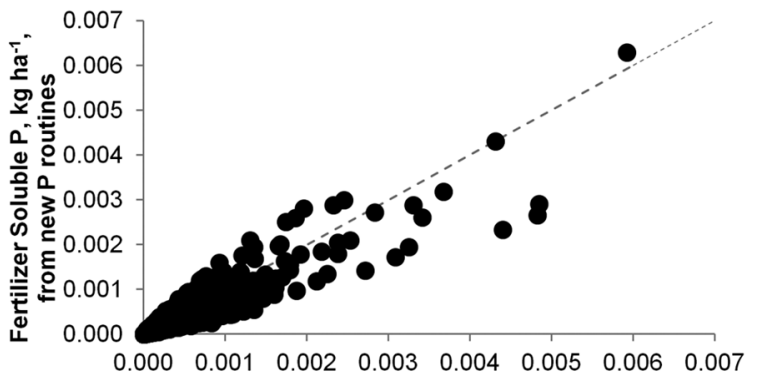

Fertilizer Soluble $\mathbf{P}, \mathbf{k g ~ h a}^{-1}$, from standard $\mathbf{P}$ routines

B.

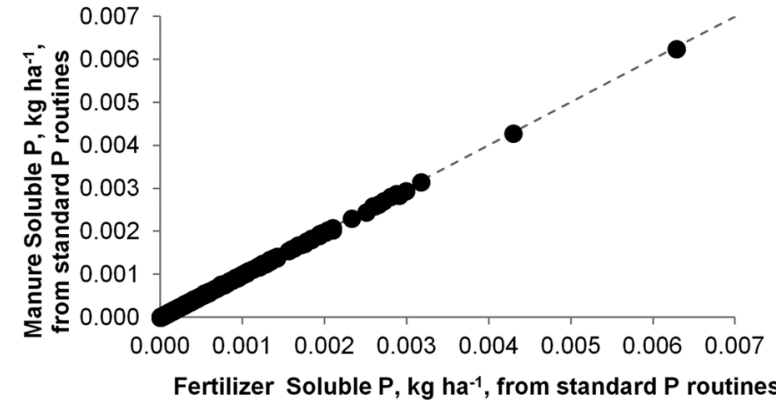

C.

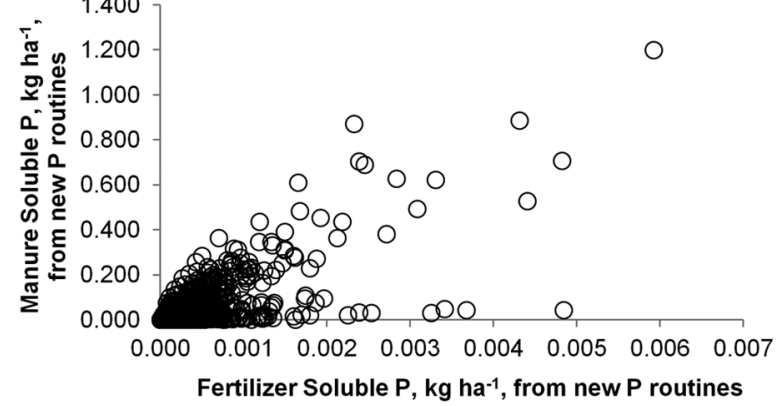

Fig. 7. Effect of application form (mineral $P$ vs. manure $P$ ) on soluble $P$ losses between standard and new $P$ routines: (a) mineral $P$ in new routines vs. mineral $P$ in standard routines, (b) manure $P$ in standard routines vs. mineral $P$ in standard routines, and (c) manure $P$ in new routines vs. mineral $P$ in new routines.

application (when compared with disk incorporation). Given the pervasive nature of the standard P routines used by SWAT, also found in APEX (Williams et al., 2000), Hydrologic Simulation Program-Fortran (Bicknell et al., 1993), Agricultural Non-Point Source Pollution Model (Binger and Theurer, 2009), and others (e.g., Pierson et al., 2001), our research points to the imperative for revisions to these routines.

Future field-level evaluation in a watershed with field measured runoff and more consistent management rotations will help elucidate impacts due to crop cover, management, and within-field variations. Additionally, evaluation in a watershed with less topographic relief may be of interest to determine if conventional SWAT and TopoSWAT perform similarly under the new $\mathrm{P}$ routines across the $4 \mathrm{R}$ factors. This may provide additional insight into the importance of new $\mathrm{P}$ routines in conventional SWAT for large watershed studies where TopoSWAT is computationally less feasible.

\section{ACKNOWLEDGMENTS}

The authors thank the USDA-NRCS Conservation Innovation Grants (CIG) for financial support in part as well as the strong collaborations of the CIG project teams. The authors also thank Gordan Folmar and Jim Richards from USDA-ARS for providing watershed hydrology data and field management information, respectively.

\section{References}

Arnold, J.G., P.M. Allen, M. Volk, J.R. Williams, and D.D. Bosch. 2010 Assessment of different representations of spatial variability on SWAT model performance. Trans. ASABE 53(5):1433-1443. doi: $10.13031 / 2013.34913$

Arnold, J.G., D. Moriasi, P.W. Gassman, K.C. Abbaspour, M.J. White, R. Srinivasan, C. Santhi, R.D. Harmel, A. van Griensven, M.W. Van Liew, N. Kannan, and M. Jha. 2012. SWAT: Model use, calibration, and validation. Trans. ASABE 55(4):1491-1508. doi:10.13031/2013.42256

Beven, K.J., and M.J. Kirkby. 1979. A physically based, variable contributing area model of basin hydrology/Un modè̀le al base physique de zone d'appel variable de l'hydrologie du bassin versant. Hydrol. Sci. Bull. 24(1):43-69. doi:10.1080/02626667909491834

Bicknell, B.R., J.C. Imhoff, J.L. Kittle, Jr., A.S. Donigian, Jr., and R.C. Johanson. 1993. Hydrologic simulation program-FORTRAN user's manual for Release 10. EPA/600/R-93/174, USEPA, Athens, GA.

Binger, R.L., and F.D. Theurer. 2009. Agricultural non-point source pollution model. USDA-ARS National Sedimentation Laboratory, Oxford, MS. http://www.ars.usda.gov/Research/docs.htm?docid=5199 (accessed 28 Feb. 2015)

Bonumá, N.B., C.G. Rossi, J.G. Arnold, J.M. Reichert, J.P. Minella, P.M. Allen, M. Volk. 2012. Simulating landscape sediment transport capacity by using a modified SWAT model. J. Environ. Qual. 43:55-66. doi:10.2134/ jeq2012.0217.

Bryant, R.B., T.L. Veith, G.W. Feyereisen, A.R. Buda, C.D. Church, G.J. Folmar, J.P. Schmidt, C.J. Dell, and P.J.A. Kleinman. 2011. USDA-ARS Mahantango Creek Watershed, Pennsylvania, United States: Physiography and history. Water Resour. Res. 47. doi:10.1029/2010WR010056

Buda, A.R., P.J.A. Kleinman, R.B. Bryant, G.W. Feyereisen, D.A. Miller, P.G. Knight, and P.J. Drohan. 2013. Forecasting runoff from Pennsylvania landscapes. J. Soil Water Conserv. 68:185-198. doi:10.2489/ jswc.68.3.185

Buda, A.R., P.J.A. Kleinman, M.S. Srinivasan, R.B. Bryant, and G.W. Feyereisen. 2009a. Effects of hydrology and field management on phosphorus transport in surface runoff. J. Environ. Qual. 38:2273-2284. doi:10.2134/ jeq2008.0501

Buda, A.R., P.J.A. Kleinman, M.S. Srinivasan, R.B. Bryant, and G.W. Feyereisen. 2009b. Factors influencing surface runoff generation from two agricultural hillslopes in central Pennsylvania. Hydrol. Processes 23:1295-1312. doi:10.1002/hyp. 7237

Chesapeake Executive Council. 2014. Chesapeake Bay watershed agreement. Chesapeake Bay Program, Annapolis, MD. http://www.chesapeakebay. net/documents/FINAL_Ches_Bay_Watershed_Agreement. withsignatures-HIres.pdf (accessed 28 Feb. 2015).

Collick, A.S., D.R. Fuka, P.J.A. Kleinman, A.R. Buda, J.L. Weld, M.J. White, T.L. Veith, R.B. Bryant, C.H. Bolster, and Z.M. Easton. 2015. Predicting phosphorus dynamics in complex terrains using a variable source area hydrology model. Hydrol. Processes 29:588-601. doi:10.1002/hyp.10178

Coover, J.B. 2012. Phosphorus sorption and desorption in ephemeral gully erosion. M.S. thesis. Kansas State Univ., Manhattan, KS.

Easton, Z.M., D.R. Fuka, M.T. Walter, D.M. Cowan, E.M. Schneiderman, and T.S. Steenhuis. 2008. Re-conceptualizing the Soil and Water Assessment Tool (SWAT) model to predict runoff from variable source areas. J. Hydrol. 348:279-291. doi:10.1016/j.jhydrol.2007.10.008

Easton, Z.M., M.T. Walter, D.R. Fuka, E.D. White, and T.S. Steenhuis. 2011. A simple concept for calibrating runoff thresholds in quasi-distributed variable source area watershed models. Hydrol. Proc. 25:3131-3143. doi: $10.1002 /$ hyp. 8032

Edwards, D.R., and T.C. Daniel. 1993. Effects of poultry litter application rates and rainfall intensity on quality of runoff from fescue plots. J. Environ. Qual. 22:361-365. doi:10.2134/jeq1993.00472425002200020017x

Elliott, H.A., R.C. Brandt, P.J.A. Kleinman, A.N. Sharpley, and D.B. Beegle. 2006. Estimating source coefficients for phosphorus site indices. J. Environ. Qual. 35:2195-2201. doi:10.2134/jeq2006.0014

ESRI. 2012. ArcGIS Desktop Release 10. Environmental Systems Research Institute, Redlands, CA.

FAO-UNESCO. 2007. GeoNetwork opensource. FAO Land and Water Development Division, Rome. http://www.fao.org/geonetwork/srv/en/ main.home\# (verified 24 Feb. 2016).

Fuka, D.R. 2013. Simplifying watershed modeling. Ph.D. diss. Cornell Univ., Ithaca, NY.

Ghebremichael, L.T., T.L. Veith, J.M. Hamlett, and W.J. Gburek. 2008. Precision feeding and forage management effects on phosphorus loss modeled at a watershed scale. J. Soil Water Conserv. 63:280-291. doi:10.2489/ jswc.63.5.280 
Ghebremichael, L.T., T.L. Veith, and M.C. Watzin. 2010. Determination of critical source areas for phosphorus loss: Lake Champlain basin, Vermont. Trans. ASABE 53:1595-1604

Geirard-Marchant, P., W.D. Hively, and T.S. Steenhuis. 2005. Simple models for phosphorus loss from manure in runoff. J. Environ. Qual. 34:872-876.

Harmel, R.D., D.R. Smith, R.L. Haney, and M. Dozier. 2009. Nitrogen and phosphorus runoff from cropland and pasture fields fertilized with poultry litter. J. Soil Water Conserv. 64:400-412. doi:10.2489/jswc.64.6.400

IPNI (International Plant Nutrition Institute). 2012. History of the "4Rs". International Plant Nutrition Institute, Peachtree Corners, GA. http:// www.ipni.net/article/IPNI-3284 (accessed 28 Feb. 2015).

Kleinman, P.J.A., and A.N. Sharpley. 2003. Effect of broadcast manure on runoff phosphorus concentrations over successive rainfall events. J. Environ. Qual. 32:1072-1081. doi:10.2134/jeq2003.1072

Kleinman, P.J.A., A.N. Sharpley, T.L. Veith, R.O. Maguire, and P.A. Vadas. 2004. Evaluation of phosphorus transport in surface runoff from packed soil boxes. J. Environ. Qual. 33:1413-1423. doi:10.2134/jeq2004.1413

Kleinman, P.J.A., M.S. Srinivasan, C.J. Dell, J.P. Schmidt, A.N. Sharpley, and R.B. Bryant. 2006. Role of rainfall intensity and hydrology in nutrient transport via surface runoff.J. Environ. Qual. 35:1248-1259. doi:10.2134/ jeq2006.0015

Kleinman, P.J.A., D. Sullivan, A. Wolf, R. Brandt, Z. Dou, H. Elliott, J. Kovar, A. Leytem, R. Maguire, P. Moore, L. Saparito, A. Sharpley, A. Shober, T. Sims, J. Toth, G. Toor, H. Zhang, and T. Zhang. 2007. Selection of a water extractable phosphorus test for manures and biosolids as an indicator of runoff loss potential. J. Environ. Qual. 36:1357-1367. doi:10.2134/ jeq2006.0450

Kleinman, P.J.A., A.N. Sharpley, L.S. Saporito, A.R. Buda, and R.B. Bryant. 2009. Application of manure to no-till soils: Phosphorus losses by subsurface and surface pathways. Nutr. Cycling Agroecosyst. 84:215-227. doi: $10.1007 /$ s10705-008-9238-3

Moriasi, D.N., J.G. Arnold, M.W. Van Liew, R.L. Bingner, R.D. Harmel, and T.L. Veith. 2007. Model evaluation guidelines for systematic quantification of accuracy in watershed simulations. Trans. ASABE 50(3):885-900. doi: $10.13031 / 2013.23153$

Nash, J.E., and J.V. Sutcliffe. 1970. River flow forecasting through conceptual models part I: a discussion of principles. J. Hydrol. 10:282-290.

Neitsch, S.L., J.G. Arnold, J.R. Kiniry, R. Srinivasan, and J.R. Williams. 2011. Soil and water assessment tool theoretical documentation. Rep. TR-406. Texas Water Resources Inst., College Station, TX. http://swat.tamu.edu/ documentation/ (accessed 28 Feb. 2015).

Pierson, S.T., M.L. Cabrera, G.K. Evanylo, P.D. Schroeder, D.E. Radcliffe, H.A. Kuykendall, V.W. Benson, J.R. Williams, C.S. Hoveland, and M.A. McCann. 2001. Phosphorus losses from grasslands fertilized with broiler litter: EPIC simulations. J. Environ. Qual. 30:1790-1795. doi:10.2134/ jeq2001.3051790x

Pierzynski, G.M., editor. 2000. Methods of phosphorus analysis for soils, sediments, residuals, and waters. Southern Cooperative Series Bul. 396. North Carolina State Univ., Raleigh, NC.

Pote, D.H., T.R. Way, P.J.A. Kleinman, P.A. Moore, J.J. Meisinger, K.R. Sistani, L.S. Saporito, A.L. Allen, and G.W. Feyereisen. 2011. Subsurface application of poultry litter in pasture and no-till soils. J. Environ. Qual. 40:402-411. doi: 10.2134/jeq2010.0352

Preedy, N., K. McTiernan, R. Matthews, L. Heathwaite, and P. Haygarth. 2001. Rapid incidental phosphorus transfers from grassland. J. Environ. Qual. 30:2105-2112. doi:10.2134/jeq2001.2105

Radcliffe, D.E., K. Blombäck, C.H. Bolster, A.S. Collick, Z.M. Easton, W. Francesconi, D.R. Fuka, H. Johnsson, M. Larsbo, Y.A. Mohamed, A.S. Mulkey, N.O. Nelson, K. Persson, J.J. Ramirez-Avila, D.K. Reid, F. Schmieder, and D.R. Smith. 2015. Applicability of current models to prediction of phosphorus losses in artificially drained fields: A review. J. Environ. Qual. 44:614-628. doi:10.2134/jeq2014.05.0220
Radcliffe, D.E., J. Freer, and O. Schoumans. 2009. Diffuse phosphorus models in the United States and Europe: Their usages, scales, and uncertainties. J. Environ. Qual. 38:1956-1967. doi:10.2134/jeq2008.0060

Rossi, C.G., D.M. Heil, N.B. Bonumí, and J.R. Williams. 2012. Evaluation of the Langmuir model in the Soil and Water Assessment Tool for a high soil phosphorus condition. Environ. Model. Softw. 38:40-49. doi:10.1016/j. envsoft.2012.04.018

Sedorovich, D.M., C.A. Rotz, P.A. Vadas, and R.D. Harmel. 2007. Predicting management effects on phosphorus loss from farming systems. Trans. ASAE 50(4):1443-1453. doi:10.13031/2013.23617

Sen, S., P. Srivastava, P.A. Vadas, and L. Kalin. 2012. Watershed-level comparison of predictability and sensitivity of two phosphorus models. J. Environ. Qual. 41:1642-1652. doi:10.2134/jeq2011.0242

Sharpley, A.N. 1985. Depth of surface soil-runoff interaction as affected by rainfall, soil slope and management. Soil Sci. Soc. Am. J. 49:1010-1015. doi: 10.2136/sssaj1985.03615995004900040044x

Sharpley, A.N., P.J.A. Kleinman, R.W. McDowell, M. Gitau, and R.B. Bryant. 2002. Modeling phosphorus transport in agricultural watersheds: Processes and possibilities. J. Soil Water Conserv. 57:425-439.

Soil Survey Staff. 2015. Web Soil Survey. USDA Natural Resources Conservation Service. http://websoilsurvey.nrcs.usda.gov/ (accessed 1 Mar. 2015).

Vadas, P.A., C.H. Bolster, and L.W. Good. 2013. Critical evaluation of models used to study agricultural phosphorus and water quality. Soil Use Manage. 29:36-44. doi:10.1111/j.1475-2743.2012.00431.x

Vadas, P.A., W.J. Gburek, A.N. Sharpley, P.J.A. Kleinman, P.A. Moore, Jr., M.L. Cabrera, and R.D. Harmel. 2007a. A model for phosphorus transformation and runoff loss for surface-applied manures. J. Environ. Qual. 36:324-332. doi: $10.2134 /$ jeq2006.0213

Vadas, P.A., R.D. Harmel, and P.J.A. Kleinman. 2007b. Transformations of soil and manure phosphorus after surface application of manure to field plots. Nutr. Cycling Agroecosyst. 77:83-99. doi:10.1007/s10705-006-9047-5

Vadas, P.A., B.C. Joern, and P.A. Moore, Jr. 2012. Simulating soil phosphorus dynamics for a phosphorus loss quantification tool. J. Environ. Qual. 41:1750-1757. doi:10.2134/jeq2012.0003

Vadas, P.A., P.J.A. Kleinman, and A.N. Sharpley. 2004. A simple method to predict dissolved phosphorus in runoff from surface applied manures. J. Environ. Qual. 33:749-756. doi:10.2134/jeq2004.7490

Vadas, P.A., P.J.A. Kleinman, A.N. Sharpley, and B.L. Turner. 2005. Relating soil phosphorus to dissolved phosphorus in runoff: A single extraction coefficient. J. Environ. Qual. 34:572-580. doi:10.2134/jeq2005.0572

Vadas, P.A., T. Krogstad, and A.N. Sharpley. 2006. Modeling phosphorus transfer between labile and non-labile soil pools: updating the epic model. Soil Sci. Soc. Am. J. 70:736-743. doi:10.2136/sssaj2005.0067

Veith, T.L., A.N. Sharpley, and J.G. Arnold. 2008. Modeling a small, northeastern watershed with detailed, field-level data. Trans. ASABE 51(2):471-483. doi: $10.13031 / 2013.24389$

Veith, T.L., A.N. Sharpley, J.L. Weld, and W.J. Gburek. 2005. Comparison of measured and simulated phosphorus losses with indexed site vulnerability. Trans. ASAE 48(2):557-565. doi:10.13031/2013.18330

Williams, J.R., J.G. Arnold, and R. Srinivasan. 2000. The APEX Model. BRC Rep. No. 00-06. Texas A\&M Blackland Research Center, Temple, TX. 